\title{
Introduction of prognostic rain in ECHAM5: design and single column model simulations
}

\author{
R. Posselt and U. Lohmann \\ Institute for Atmospheric and Climate Science, ETH Zurich, Universitaetsstrasse 16, 8092 Zurich, Switzerland \\ Received: 14 September 2007 - Published in Atmos. Chem. Phys. Discuss.: 15 October 2007 \\ Revised: 7 May 2008 - Accepted: 13 May 2008 - Published: 12 June 2008
}

\begin{abstract}
Prognostic equations for the rain mass mixing ratio and the rain drop number concentration are introduced into the large-scale cloud microphysics parameterization of the ECHAM5 general circulation model (ECHAM5-PROG). To this end, a rain flux from one level to the next with the appropriate fall speed is introduced. This maintains rain water in the atmosphere to be available for the next time step. Rain formation in ECHAM5-PROG is, therefore, less dependent on the autoconversion rate than the standard ECHAM5 but shifts the emphasis towards the accretion rates in accordance with observations. ECHAM5-PROG is tested and evaluated with Single Column Model (SCM) simulations for two cases: the marine stratocumulus study EPIC (October 2001) and the continental mid-latitude ARM Cloud IOP (shallow frontal cloud case - March 2000). In case of heavy precipitation events, the prognostic equations for rain hardly affect the amount and timing of precipitation at the surface in different SCM simulations because heavy rain depends mainly on the large-scale forcing. In case of thin, drizzling clouds (i.e., stratocumulus), surface precipitation is sensitive to the number of sub-time steps used in the prognostic rain scheme. Cloud microphysical quantities, such as cloud liquid and rain water within the atmosphere, are sensitive to the number of sub-time steps in both considered cases. This results from the decreasing autoconversion rate and increasing accretion rate.
\end{abstract}

\section{Introduction}

Clouds and precipitation play an important role in the hydrological cycle of the Earth. Changing precipitation patterns due to climate change will result in shifted vegetation

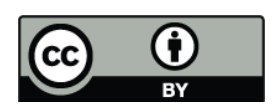

Correspondence to: R. Posselt (rebekka.posselt@env.ethz.ch) zones, will have an influence on water quality, soil structure/erosion and runoff into rivers and oceans (Hatfield and Prueger, 2004). Through feedback processes, these changed precipitation rates have an impact on cloud formation and microphysical processes which, on their part, influence the precipitation rates. Recently, the impact of aerosol particles resulting from human activity on cloud and precipitation formation received a lot of attention (e.g., Denman et al., 2007; Penner et al., 2006; Storelvmo et al., 2006; Lohmann and Feichter, 2005; Rosenfeld, 2000). Thus, a proper treatment of cloud microphysical processes in models, especially in General Circulation Models (GCM) like the ECHAM5, is necessary to obtain reliable predictions of the aerosol indirect effects (Twomey, 1974; Albrecht, 1989) on clouds and precipitation and hence, on the radiative budget of the Earthatmosphere system.

The formation of precipitation in a GCM is closely related to the parameterization of cloud microphysical processes. An assumption that is widely used in GCMs is that the sedimentation of rain drops is very fast compared to the model time step. Hence, all precipitation particles formed within one time step will fall through the whole vertical column within the same time step. On the way down, they can evaporate and participate in the accretion process. The disadvantage of this concept is that, for each time step, the rain drops first have to be newly produced by autoconversion. Observations indicate that this process is less important in the atmosphere than accretion of cloud droplets by rain (Wood, 2005; Pruppacher and Klett, 1997; Rogers and Yau, 1989). The evaluation of profiles from in-situ microphysical measurements from 12 flights over the ocean (close to the UK) by Wood (2005) revealed that accretion is the most relevant process for drizzle production in the lower $80 \%$ of the cloud. In the upper $20 \%$ of the cloud, autoconversion and accretion are equally important. Thus, the concept of diagnostic precipitation assesses the in-cloud conversion processes unrealistically by putting too much emphasis on the autoconversion rate.

Published by Copernicus Publications on behalf of the European Geosciences Union. 
The motivation for this study is to investigate the influence of giant cloud condensation nuclei (GCCN) on the warm rain formation. GCCN are regarded as aerosol particles larger than $5-10 \mu \mathrm{m}$ in radius (Johnson, 1982; Feingold et al., 1999). Seeding GCCN into a non-precipitation cloud (due to high amounts of anthropogenic aerosol particles) might initiate precipitation due to an enhanced collection of small cloud droplets by the larger drops that originate from GCCNs. Therefore, GCCN could counteract the aerosol indirect effects (e.g., Johnson, 1982; Feingold et al., 1999; Rosenfeld et al., 2002). The resulting precipitation can be regarded as drizzle as the drops are rather small and the total precipitation rate is low. Therefore, the assumption that all rain is removed within one model time step might not hold for these clouds. Lower fall speeds in the model imply that part of the rain water is kept in the atmosphere and is available for the next model time step. To keep track of the rain water in the atmosphere, rain has to be treated prognostically in the model instead of diagnostically.

Several large scale microphysics schemes (e.g., Lohmann and Roeckner, 1996; Rotstayn, 1997) treat precipitation diagnostically so that all precipitation is removed from the atmosphere within one model time step. This is justified as using diagnostic precipitation allows for longer model time steps without significantly changing the temporal evolution of cloud water and ice (Ghan and Easter, 1992). Nevertheless, some GCMs treat the precipitation prognostically by including sedimentation of precipitation. Fowler et al. (1996) implemented a one-moment microphysics scheme into the $\mathrm{CSU}^{1} \mathrm{GCM}$ accounting for changes in water vapor, cloud water and cloud ice, rain and snow. The microphysical processes include condensation/evaporation of cloud water, deposition/sublimation of cloud ice, evaporation of rain/snow, melting of snow and freezing of rain, collisions between the hydrometeor classes (i.e., autoconversion, accretion) and the Bergeron-Findeisen process. The precipitation processes including the sedimentation of rain and snow are treated with a small time step ( $2 \mathrm{~min}$ ) using a time-splitting method. A mass-weighted fall speed for rain and snow is applied in the sedimentation scheme. Lopez (2002) incorporated a largescale cloud scheme into Meteo France's operational global model ARPEGE ${ }^{2}$. It uses cloud condensate and precipitation as prognostic variables. Microphysical processes include condensation/evaporation of cloud condensate, evaporation of precipitation, autoconversion and accretion. The sedimentation of precipitation is done in a simple semi-Lagrangian framework assuming constant fall velocities for rain $\left(5 \mathrm{~ms}^{-1}\right)$ and snow $\left(0.9 \mathrm{~ms}^{-1}\right)$. The implementation of moist processes including rain sedimentation into the $\mathrm{EULAG}^{3}$ model is described by Grabowski and Smolarkiewicz (2002). The

\footnotetext{
${ }^{1}$ Colorado State University

${ }^{2}$ Action de Recherche Petite Echelle et Grande Echelle

${ }^{3}$ EUlerian - semi-LAGrangian model (Smolarkiewicz and Margolin, 1997)
}

EULAG model is a multi-scale model covering cloud resolving scales up to global scales. The microphysical parameterizations (Grabowski, 1998) are given for cloud condensate and precipitation and include condensation of water vapor, autoconversion of cloud condensate into precipitation and accretion of cloud condensate by precipitation, as well as deposition/evaporation of precipitation. The cloud microphysical processes are evaluated on time steps appropriate for the considered problem which can be smaller than the model dynamics time step. The sedimentation of precipitation is determined by a one-dimensional flux-form advection scheme. Global simulations deploy time steps of $30 \mathrm{~s}$ for a secondorder explicit scheme (MPDATA, Smolarkiewicz and Margolin, 1998) or $600 \mathrm{~s}$ for an implicit upwind scheme for the precipitation simulations.

This paper focuses on the introduction of prognostic equations for the rain mass mixing ratio and the rain drop number concentration into the large-scale cloud scheme within ECHAM5. An explicit fall speed for the sedimentation of rain drops is derived that depends on the rain drop size. The precipitation processes are calculated on smaller time steps using a time-splitting method. Thus, a better representation of the microphysical processes in which rain is involved is achieved. In case of the applied explicit numerical scheme for the sedimentation, the time-stepping is also necessary to assure numerical stability. As this study focuses on warm phase precipitation formation, snow is still treated diagnostically. GCCN are included in the second part of this study (Posselt and Lohmann, 2007).

Results from a single column simulation with the newly introduced prognostic rain will be presented. Single column model (SCM) simulations are conducted with a case from the EPIC $^{4}$ stratocumulus study that took place in September and October 2001 in the eastern Pacific (off the coast of Ecuador and Peru) (Bretherton et al., 2004). A second SCM case is derived from ARM IOP ${ }^{5}$ measurements. The shallow frontal cloud case of the Cloud IOP (Xu et al., 2005) that took place in March 2000 at the ARM Southern Great Plain Site in Oklahoma is chosen. For these two cases, changes in precipitation and the cloud properties due to the introduction of the prognostic equations for rain will be investigated. The results from these simulations will be compared to ECHAM5-DIAG (Lohmann et al., 2007) and to observations from EPIC and ARM.

\footnotetext{
${ }^{4}$ Eastern Pacific Investigation of Climate Processes

${ }^{5}$ Atmospheric Radiation Measurement program, Intensive Operational Period
} 


\section{Model description}

\subsection{The general circulation model ECHAM5}

The ECHAM5-GCM is based on the ECMWF model and has been further developed at the Max-Planck-Institute for Meteorology in Hamburg. Within ECHAM5 the prognostic equations for temperature, surface pressure, divergence and vorticity are solved on a spectral grid with a triangular truncation (Roeckner et al., 2003). The used ECHAM5-DIAG version comprises a two-moment cloud scheme with prognostic equations for cloud water (ice) and cloud drop (ice crystal) number concentration and includes a coupling between aerosols and cloud scheme (Lohmann and Roeckner, 1996; Lohmann et al., 1999, 2007). Within the aerosol module HAM (Stier et al., 2005), atmospheric aerosol distributions are represented by a double moment scheme consisting of a superposition of 7 lognormal distributions of different size ranges, solubilities, and chemical constituents. For the simulations in this study the statistical cloud cover scheme of Tompkins (2002) is used.

\subsection{Prognostic equations for rain}

Within ECHAM5-DIAG, rain is treated diagnostically and the total rain water is removed from the model after one time step (as surface precipitation flux) or by evaporation in the sub-saturated air below the cloud. This approach is only realistic for relatively large rain drops $(r>100 \mu \mathrm{m})$. Smaller drops, i.e., drizzle $(25 \mu \mathrm{m}<r<100 \mu \mathrm{m})$, also sediment but may not reach the surface within one time step. To account for this behavior, prognostic equations for rain are introduced to ECHAM5-DIAG, in the following referred to as ECHAM5-PROG, with the following processes. Firstly, a rain flux enters a given level from above and leaves this level due to the sedimentation of rain drops (sed). New rain drops form by autoconversion of cloud droplets (aut). The rain drop number decreases by self collection (scr) of rain drops. An increase in rain water is caused by accretion of cloud droplets by rain drops (acr). The evaporation of rain (evpr) in the subsaturated air below cloud leads to a decrease of rain water mass and rain drop number, whereas, the melting of snow (mls) causes an increase in rain drop mass and number. A further source for rain water and number is the direct activation of GCCN (nucr) into rain drops which is not included in this paper but in the second part of this study (Posselt and Lohmann, 2007). The rates of rain water mixing ratio $\partial q / \partial t$ and rain drop number concentration $\partial N / \partial t$ due to these processes are summarized in Eq. (1). $Q$ and $P$ denote changes in the rain water mixing ratio and in the rain drop number concentration, respectively.

$$
\begin{aligned}
\frac{\partial q}{\partial t}= & Q_{\mathrm{nucr}}+b_{c}\left(Q_{\mathrm{aut}}+Q_{\mathrm{acr}}\right) \\
& -\left(1-b_{r}\right) Q_{\mathrm{evpr}}+b_{r}\left(Q_{\mathrm{mls}}+Q_{\mathrm{sed}}\right) \\
\frac{\partial N}{\partial t}= & P_{\mathrm{nucr}}+b_{c}\left(P_{\mathrm{aut}}\right)-\left(1-b_{r}\right) P_{\mathrm{evpr}} \\
& +b_{r}\left(P_{\mathrm{mls}}-P_{\mathrm{scr}}+P_{\mathrm{sed}}\right)
\end{aligned}
$$

The cloud cover $b_{c}$ is calculated with the statistical cloud cover scheme by Tompkins (2002). A beta distribution is assumed as the probability density function (PDF) for the total water $q_{t}$ (water vapor+cloud water+cloud ice) of the grid box. The cloud cover is then defined as the integral over the saturated part of the PDF (i.e., for $q_{t}>q_{s}$, with $q_{s}$ denoting the saturation specific humidity). The precipitation fraction $b_{r}$ is determined by the cloud fraction of the precipitating cloud. Following the precipitation on its way from the cloud base to the surface a maximum overlap of $b_{r}$ is assumed which is consistent with the maximum cloud overlap assumption of $b_{c}$ within the cloud microphysics routine.

Except for the rain flux, all microphysical processes are already part of ECHAM5-DIAG and are now also included in the prognostic equations for rain. The parameterization of the microphysical processes (aut and acr) are taken from Khairoutdinov and Kogan (2000). Lacking a parameterization for the self-collection of rain drops by Khairoutdinov and Kogan (2000), $P_{\text {scr }}$ is parameterized according to Beheng (1994). The reduction of rain water mass due to evaporation is parameterized according to Rotstayn (1997). Furthermore, it is assumed that the rain drop number concentration is reduced proportional to the rain water mass so that the mean rain drop size stays constant (Khairoutdinov and Kogan, 2000). Snow is still treated diagnostically, i.e. all snow will be removed from the atmosphere within one model time step either by melting (generating rain), by sublimation or as surface precipitation. To be consistent, snow should also be treated prognostically but this is beyond the scope of this study. Because only the snow mass is given the size of the melted snow is assumed to be $25 \mu \mathrm{m}$. This size is chosen according to the separation size for cloud droplets and rain drops proposed by Khairoutdinov and Kogan (2000). The calculation of the incoming and outgoing rain fluxes is described in the next section.

\subsection{Rain flux and rain drop sedimentation}

The sedimentation of the rain drops and, with it, the rain flux from one model level to the next is treated as a vertical 1-Dadvection with the mass and number weighted fall velocity $v_{q}$ and $v_{N}$ (positive in downward direction) of the rain water mass mixing ratio $q\left[\mathrm{~kg} \mathrm{~kg}^{-1}\right]$ and rain drop number concentration $N\left[\mathrm{~m}^{-3}\right]$, respectively. Using different fall speeds for mass and number emulate the fact that large and heavy drops fall faster than small drops. The advection equation 
is expressed in flux form to account for changes in rain water mass and number with changing density, i.e., with height. Therefore, it is more convenient to express the number of rain drops as mixing ratio $n=N / \rho_{a}\left(n\right.$ in $\left.\left[\mathrm{kg}^{-1}\right]\right)$ with $\rho_{a}$ denoting the air density.

$$
\begin{gathered}
Q_{\text {sed }}=\left.\frac{\partial q}{\partial t}\right|_{\text {sed }}=\frac{1}{\rho_{a}} \frac{\partial}{\partial z}\left(\rho_{a} q v_{q}\right) \\
P_{\text {sed }}=\left.\frac{\partial n}{\partial t}\right|_{\text {sed }}=\frac{1}{\rho_{a}} \frac{\partial}{\partial z}\left(\rho_{a} n v_{N}\right)
\end{gathered}
$$

The numerical solution is found by an upstream scheme in space and a forward scheme in time. The decision for this explicit scheme has several reasons. First of all, the scheme is mass conserving by definition which is very important when dealing with cloud microphysics. The microphysical processes are treated sequentially, i.e., one after the other, in each level starting from the top level to the bottom. The sedimentation into the next level takes place after the cloud microphysical processes. This "stepwise" sedimentation requires the determination of outgoing and incoming quantities separately (i.e., in level $i$ : determine what is going out of level $i$ and what is getting into level $i+1$ ). A more sophisticated explicit scheme (like, e.g., MPDATA with correction steps, Smolarkiewicz and Margolin, 1998) would however require a total restructuring of the model with a separation between microphysical processes and sedimentation. This in turn would require an extensive retuning of the model. Furthermore, sensitivity studies comparing explicit and implicit sedimentation schemes yield similar results (Müller, 2007). Nevertheless, an explicit scheme without correction steps is very diffusive and has low spatial and temporal discretization abilities. Therefore, once it is shown that the implementation of the prognostic rain scheme is beneficial for the representation of clouds and precipitation, a more sophisticated sedimentation scheme will be implemented in the future.

To calculate the actual rain flux from one model level to the next an approach for the fall velocity of rain drops is introduced. To obtain the bulk sedimentation velocities for the rain water mass and the rain drop number, the flux density approach used by Srivastava (1978) (his Eqs. (48) and (49) for the mass and number flux, respectively) is applied.

$$
\begin{gathered}
\mathfrak{F}_{q}=\left(q \rho_{a}\right) \cdot v_{q}=\int_{0}^{\infty} c D^{3} f(D) v_{s}(D) d D \\
\text { with } c=\frac{\pi}{6} \rho_{w} \\
\mathfrak{F}_{N}=N \cdot v_{N}=\int_{0}^{\infty} f(D) v_{s}(D) d D
\end{gathered}
$$

Thereby, $\rho_{w}$ is the density of water and $v_{s}$ denotes the terminal velocity of a single rain drop with a diameter $D$. For the rain drop size distribution $f$ an exponential distribution - as was first put forward by Marshall and Palmer (1948) - is assumed.

$f(D)=N_{D} \exp (-\lambda D)$

The expression of $\lambda$ as function of $q$ follows Grabowski (1999).

$\lambda=\frac{1}{D_{0}}=\left(\pi \rho_{w} \frac{N_{D}}{\rho_{a} q}\right)^{\frac{1}{4}}$

In the following, $D_{0}$ will be used as distribution parameter instead of $\lambda$. In contrast to the Marshall-Palmer distribution and to the distribution by Grabowski (1999), the parameter $N_{D}$ is not constant but determined by the number of rain drops $N$ in the model so that the expressions for $N_{D}$ and $D_{0}$ become

$N_{D}=\frac{N}{D_{0}} \quad$ and $\quad D_{0}=\left(\pi \rho_{w} \frac{N}{\rho_{a} q}\right)^{-\frac{1}{3}}$.

The rain drop distribution takes then the form

$f(D)=\frac{N}{D_{0}} \exp \left(-\frac{D}{D_{0}}\right)$

Furthermore, to solve Eq. (3) it is convenient to take advantage of the moments $M^{(k)}$ of the size distribution $f(D)$. In case of an exponential distribution (such as Eq. 7), the moments can be expressed with the help of the Gamma function $\Gamma(x)$ :

$M^{(k)}=\int_{0}^{\infty} D^{k} f(D) d D=N D_{0}^{k} \Gamma(k+1)$

In terms of moments, the number concentration $N$ can be expressed as $M^{(0)}$ and the rain water mixing ratio $q=c M^{(3)} / \rho_{a}$.

The last important ingredient for Eq. (3) is the fall velocity of a single rain drop $v_{s}$ which is approximated according to Rogers et al. (1993).

$v_{s}(D)= \begin{cases}a_{1} D\left[1-\exp \left(-a_{2} D\right)\right] & D \leq 745 \mu \mathrm{m} \\ b_{1}-b_{2} \exp \left(-b_{3} D\right) & D \geq 745 \mu \mathrm{m}\end{cases}$

with $D$ denoting the diameter of the rain drop and the constants $a_{1}=4000 \mathrm{~s}^{-1}, a_{2}=12000 \mathrm{~m}^{-1}, b_{1}=9.65 \mathrm{~m} \mathrm{~s}^{-1}$, $b_{2}=10.43 \mathrm{~m} \mathrm{~s}^{-1}$, and $b_{3}=600 \mathrm{~m}^{-1}$. Unfortunately, this splitted formulation is problematic as the solution of the mass flux equation with the method of the moments requires one equation for $v_{s}$ for the whole size range. To circumvent this problem, a correction term $v_{\text {corr }}$ was added to the second equation $v_{s, 2}$ of Eq. (9) to obtain a fit to the first equation $v_{s, 1}$ of Eq. (9) at lower rain drop sizes so that the following approximation for $D \leq 745 \mu \mathrm{m}$ applies

$v_{s, 1} \simeq v_{s, 2}+v_{\text {corr }}$. 
This leads to a lower accuracy for lower rain drop sizes. Because the fall velocities are rather small, the drops in that size range do not fall very far within one model time step. Therefore, this loss of accuracy is negligible for the purpose of this application. The correction term is assumed to be an exponential function $v_{\text {corr }}=c_{1} \exp \left(-c_{2} D\right)$. The constants $c_{1}$ and $c_{2}$ are obtained by evaluating Eq. (10) at $D=0\left(v_{s, 1}=0\right.$, $\left.c_{1}=\left(b_{2}-b_{1}\right)\right)$ and for $D \rightarrow 745 \mu \mathrm{m}\left(v_{s, 1} \sim a_{1} D, c_{2} \sim 5 b_{3}\right)$. The resulting approximated equation to Eq. (9) for the fall velocity of a single rain drop is given by:

$v_{s}(D)=b_{1}-b_{2} \exp \left(-b_{3} D\right)+\left(b_{2}-b_{1}\right) \exp \left(-5 b_{3} D\right)$

The fall velocities of a single drop according to Eq. (9) (black dotted and dashed lines) as well as according to Eq. (11) are shown in Fig. 1 (upper panel) which shows that the approximated Eq. (11) fits very well to Eq. (9) by Rogers et al. (1993) over the whole size range.

Inserting the rain drop size distribution (Eq. 7) and the equation for the fall speed of a single drop (Eq. 11) into the flux equations (Eq. 3) and using the definition of the moments (Eq. 8) leads to the following asymptotic solutions for the mean fall velocity $v_{q}$ for the rain water mass and $v_{N}$ for the rain drop number:

$$
\begin{aligned}
& v_{q}=\frac{\mathfrak{F}_{q}}{\rho_{a} q}= \begin{cases}4 b_{v} D_{0} & \text { for } D_{0} \ll D_{v, q} \\
b_{1} & \text { for } D_{0} \gg D_{v, q}\end{cases} \\
& v_{N}=\frac{\mathfrak{F}_{N}}{N}= \begin{cases}b_{v} D_{0} & \text { for } D_{0} \ll D_{v, N} \\
b_{1} & \text { for } D_{0} \gg D_{v, N}\end{cases}
\end{aligned}
$$

The constant $b_{v}$ is given by $b_{v}=b_{3}\left[b_{2}-5\left(b_{2}-\right.\right.$ $\left.\left.b_{1}\right)\right]=3918 s^{-1}$. The critical distribution parameter $D_{v}$ has values of $D_{v, q}=615 \mu \mathrm{m}$ for the bulk velocity of the rain drop mass and of $D_{v, N}=2463 \mu \mathrm{m}$ for the bulk velocity of the rain drop number concentration. Therefore, for the rain drop distribution with a distribution parameter $D_{0}$ much smaller than $D_{v}$, the bulk fall velocity depends linearly on $D_{0}$ and the fall speed for $q$ is always 4 times larger than for $N$. For very large $D_{0}$ the fall speed reaches a constant value. These asymptotic solutions for the fall velocity $v_{q}$ and $v_{n}$ as a function of $D_{0}$ for drops much smaller and much larger than $D_{v}$ (dotted and dashed lines) are shown in Fig. 1 (lower panel). Sensitivity studies (partly presented in Tables 1 and 2) revealed that the model results do not depend strongly on whether a gradual transition between the two asymptotic solutions is used (simulation 10 (grad)) or not (simulation 10). Thus, a piecewise linear approximation is used for simplicity. The rain drop fall velocities $v_{q}$ and $v_{N}$ are functions of the distribution parameter $D_{0}$ and thus of the mean size of a rain drop in contrast to constant fall velocities used by Lopez (2002) or only massweighted fall velocities used by Fowler et al. (1996).

If using fall speeds for the rain drops within an explicit numerical scheme, the Courant-Friedrichs-Levy (CFL) criterion for numerical stability has to be obeyed. The CFL criterion is violated if relatively large rain drops fall too fast/too
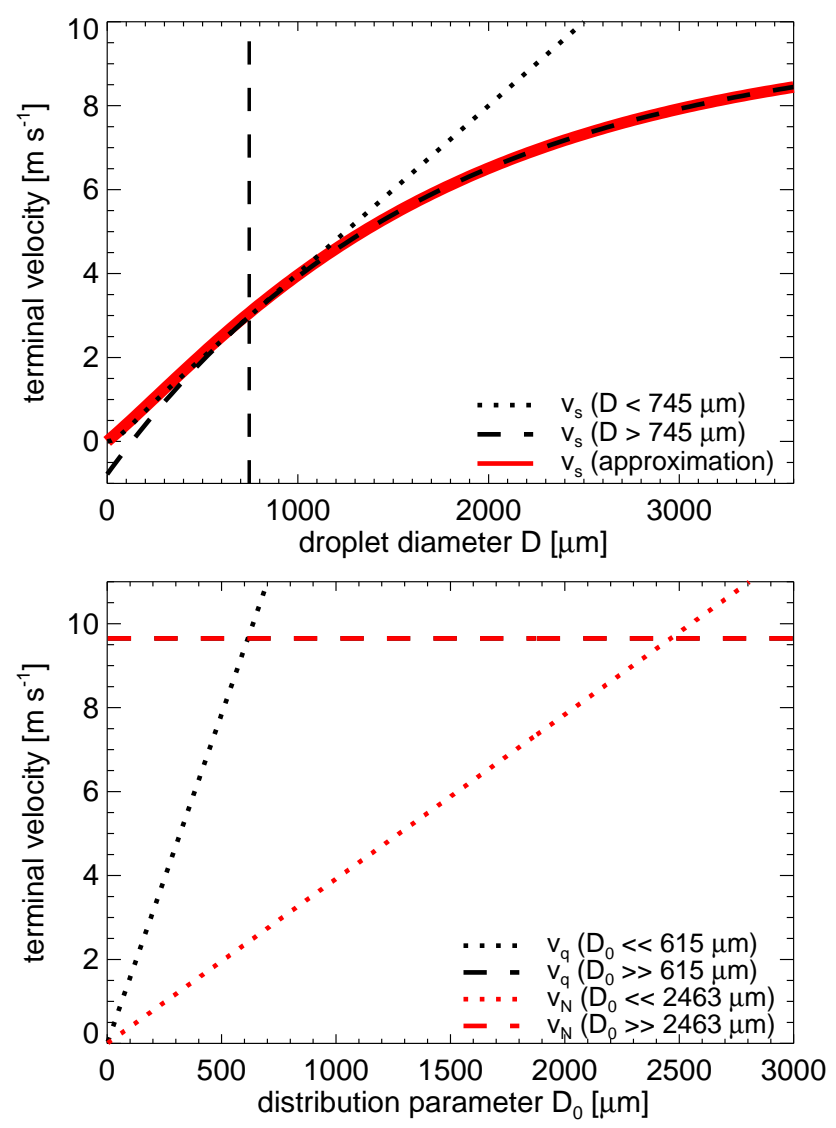

Fig. 1. Terminal velocity: The terminal velocity after Rogers et al. (1993) for small and large drops with the approximation for the whole size range (Eq. (11)=red curve) (upper panel); the fall velocity for the bulk mass and the bulk number concentration (Eq. (12)) (lower panel)

far down and, therefore, miss a model level resulting in negative rain drop mass and number. To prevent this (and the resulting chaotic behavior of the model) a reduction of the time step is necessary. Because it is computationally too expensive to be applied for the whole model, only the time step in the cloud microphysics routine is decreased. Only processes directly connected to the precipitation formation, such as autoconversion, accretion, and sedimentation are calculated using the smaller time step which also leads to a better representation of the precipitation formation via accretion. All other processes (i.e., the ice microphysics) are still calculated with the longer model time step. This requires some rearrangement in the sequence of the microphysical calculations. Given the non-linear structure of most of the microphysical parameterizations this change in sequence already cause changes in the results for the cloud and precipitation formation compared to ECHAM5-DIAG. For this paper, the number of those smaller time steps is fixed to constant values (e.g., $3,10,30, \ldots)$ that are valid for the whole simulation. Nevertheless, it is possible that the fall velocity is so 
Table 1. Mean values of precipitation, evaporation ratio, cloud cover, LWP, RWP and TWP averaged over the whole simulation period for EPIC from observations (obs) and from simulations with the standard ECHAM5-HAM (std) as well as with ECHAM5-PROG for different sub-time steps $(3,10,30$ and 100$)$ and for 10 sub-time steps with a gradual transition for the fall velocities $(10(\mathrm{grad}))$

\begin{tabular}{llccccccc}
\hline & & obs & std & 3 & 10 & 30 & 100 & 10 (grad) \\
\hline $\begin{array}{l}\text { precipitation } \\
\quad\end{array}$ & & & & & & & \\
$\quad$ cloud base & {$\left[\mathrm{mm}: d^{-1}\right]$} & 0.69 & 0.84 & 0.88 & 0.96 & 0.96 & 0.93 & 0.92 \\
Evaporation ratio & {$\left[\mathrm{mm}: d^{-1}\right]$} & 0.19 & 0.21 & 0.21 & 0.23 & 0.22 & 0.21 & 0.23 \\
LWP & & 0.73 & 0.75 & 0.77 & 0.76 & 0.78 & 0.77 & 0.75 \\
RWP & {$\left[\mathrm{g}: \mathrm{m}^{-2}\right]$} & - & 123.7 & 89.4 & 68.9 & 61.2 & 58.6 & 65.0 \\
TWP & {$\left[\mathrm{g}: \mathrm{m}^{-2}\right]$} & - & 0.0 & 4.6 & 15.6 & 20.3 & 21.2 & 15.5 \\
Cloud cover & {$\left[\mathrm{g}: \mathrm{m}^{-2}\right]$} & 102.1 & 123.7 & 94.0 & 84.2 & 81.5 & 79.7 & 80.5 \\
\hline
\end{tabular}

high that the rain drops would fall too far (especially, if they reach the lowermost model levels). For that reason, the maximum fall velocity within a level is limited by the grid velocity $v_{\max }=\Delta z / \Delta t$ which increases with increasing number of sub-time steps due to decreasing time step length $\Delta t . v_{\max }$ is necessary for numerical reasons although it does slow the sedimentation artificially, especially for larger time steps. To ensure that there are no rain drops without rain water mass, $v_{N}$ is set to $v_{\max }$ as soon as $v_{q}$ reaches $v_{\max }$ (i.e., all rain water mass is leaving the level).

\subsection{Break-up}

Spontaneous break-up for drops larger than $5 \mathrm{~mm}$ happens very rarely in real clouds as the collisional break-up prevents drop growth to these sizes (Pruppacher and Klett, 1997). In the model, break-up processes, like the collisional break-up, are not considered. Therefore, drops can grow to rather large and unrealistic sizes. To prevent this, a simple approach for the spontaneous break-up is introduced. If the number of drops larger than $D_{B}=5 \mathrm{~mm}$ in diameter (Pruppacher and Klett, 1997) exceeds $1 \%$ of the total rain drop number concentration then the rain drop distribution is changed by increasing the total rain drop number. The corresponding size distribution after the break-up has the distribution parameter $D_{0, B}$.

$\frac{1}{N} \int_{D_{B}}^{\infty} f(D) d D=\exp \left(-\frac{D_{B}}{D_{0, B}}\right)>0.01$

As soon as $D_{0} \geq D_{0, B}=1085.7 \mu \mathrm{m}$, break-up will occur. The new rain drop number concentration is then determined by $N_{B}=\left(\rho_{a} q\right) /\left(c D_{0, B}^{3}\right)=\left(\rho_{a} q\right) / 6.7 \times 10^{-7} \mathrm{~kg}$. Sensitivity studies with varying $D_{B}$ or the fraction of the total rain drop concentration yield similar results suggesting that the model is not very sensitive to these specific assumptions.

\section{Results and discussion}

\subsection{Model setup}

The following simulations are conducted with the Single Column Model (SCM) version of ECHAM5 using 31 model levels with the uppermost layer at $10 \mathrm{hPa}$. A simulation time step of $15 \mathrm{~min}$ is applied. The simulations described employ the cloud cover scheme by Tompkins (2002). The boundary conditions for the SCM are taken from datasets provided by the field campaign data archives (ARM; EPIC). The SCM is initialized by the surface pressure and the thermodynamic profiles of temperature, specific humidity and horizontal wind. The large-scale advective tendency profiles of temperature and humidity are used to force the SCM for the EPIC case. Furthermore, the sea surface temperature is given. For the ARM case, the SCM is forced with the largescale humidity tendencies. Divergence and temperature profiles are prescribed. In both cases the surface energy balance is calculated within the model, i.e., the surface fluxes are not prescribed. No nudging is applied in these simulations.

One simulation was completed with ECHAM5-DIAG which is then compared to four simulations of the altered version ECHAM5-PROG with different numbers of sub-time steps. Additionally, all simulations are compared to observations.

The discussion of the results focuses on the evolution of cloud and precipitation quantities like the precipitation flux at the surface, cloud and rain water content, cloud cover and microphysical conversion rates. Thereby changes due to the different number of sub-time steps are evaluated with the aim of finding the optimal number of sub-time steps for GCM simulations where a compromise between accuracy and computational time has to be found. Furthermore, the SCM simulations are compared to the observational data from the considered measurement campaigns. One has to bear in mind that perfect agreement between simulations and observations cannot be reached. Forcing the SCM with observations usually lacks some advective tendencies (e.g., hydro-meteor 
advection) to describe transport in and out of the model column. Therefore, the conditions at the measurement site cannot be fully reproduced by the model. Furthermore, measurements are always subject to uncertainties which also contribute to differences between model and observations. Nevertheless, the SCM is a good tool to test the new prognostic rain scheme and evaluate the behavior for different number of sub-time steps.

\subsection{Computational costs}

Splitting the cloud microphysics calculations in several subtime steps requires a larger amount of computation time than ECHAM5-DIAG with the diagnostic rain scheme. For running ECHAM5-PROG globally a balance between improvements due to the prognostic rain scheme and increasing computation times has to be found. Figure 2 shows the relative costs of CPU time depending on the number of sub-time steps. Thereby, the simulation with one sub-time step is used as baseline. The presented values are means from 10 simulation for the EPIC and ARM case studies for each number of sub-time steps. The computation time increases linearly with the number of sub-time steps (see fit in Fig. 2). A doubling of computation time would be reached for about 400 sub-time steps.

For global simulations choosing an appropriate number of sub-time steps would depend on the specific objectives. But with keeping the number of sub-time steps below 30 the increase in computation time remains below $10 \%$.

\subsection{EPIC 2001}

EPIC, the Eastern Pacific Investigation of Climate Processes (in the coupled ocean-atmosphere system) took place in September and October 2001. Besides investigating deep convection and ocean mixing, one goal was to study stratocumulus clouds and boundary layer processes. During a 2 week period in October 2001, ship-based remote sensing and ground-based measurements were taken to characterize the vertical structure of the atmospheric boundary layer and to understand the physical processes behind the stratocumulus cloud albedo. A characteristic of the campaign was an extensive stratocumulus deck which was usually organized into mesoscale cellular structures (Bretherton et al., 2004).

The EPIC Integrated Dataset of the stratocumulus study was used to force the ECHAM5 SCM. The profiles of temperature, specific humidity and horizontal wind speed were obtained from radio soundings during the campaign. The large-scale forcings, i.e. temperature and specific humidity advection, as well as the large-scale subsidence, were derived from ECMWF reanalysis data. Additionally, a cloud condensation nuclei concentration of $150 \mathrm{~cm}^{-3}$ is prescribed to obtain a cloud drop number concentration of $100-130 \mathrm{~cm}^{-3}$ which was observed during EPIC.

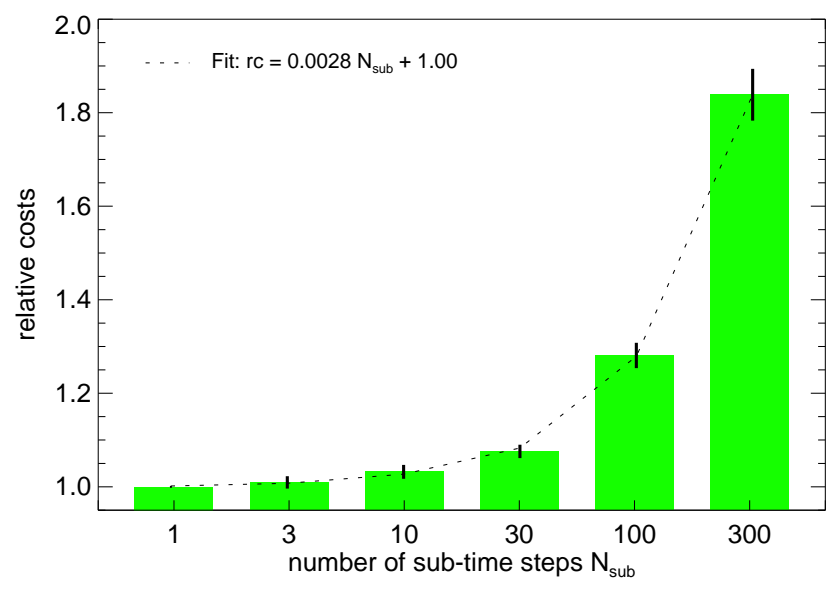

Fig. 2. Relative CPU time of simulations with different number of sub-time step compared to a simulation with one sub-time step. The vertical error bars denote the standard deviation and the dotted line represent the linear fit.

\subsubsection{Comparison to observations}

The mean values for the precipitation at the surface and at cloud base, the total cloud cover and the liquid, rain and total water path (LWP, RWP and TWP=LWP+RWP) averaged over the whole simulation period for the observations and the SCM simulations are summarized in Table 1.

On average, the ECHAM5-DIAG and ECHAM5-PROG simulations precipitate more at cloud base as well as at the surface than the observations (see Table 1). As can be seen in Fig. 3, all simulations reproduces some of the measured peaks correctly with regard to the timing but the precipitation amount does not fit. On the other hand, there are several rain events that the model totally misses (especially at the beginning of the simulation period) or that are simulated but not observed. The prognostic rain scheme does not change the deficiency of totally missing some precipitation events. It only affects the precipitation amounts slightly. Evaporation of rain below cloud base is captured quite well (see Table 1). All simulations overestimate the evaporation by less then $10 \%$ compared to the observations without considerable differences between diagnostic and prognostic rain scheme.

Reasons for the differences between observed and simulated rain can be due to the forcing data set so that the model is not able to reproduce the meteorological conditions correctly. Especially the advective tendencies are only given for the atmospheric boundary layer. Above they are set to zero, which might be a major reason for the discrepancies. According to moisture budget analysis (Yanai et al., 1973), the amount of precipitation depends also on the amount of evaporation from the surface. Under- or overestimation of the internally calculated surface fluxes can thus also contribute to the differences in the precipitation. Furthermore, ECHAM5 might be missing some essential processes (e.g., embedded 

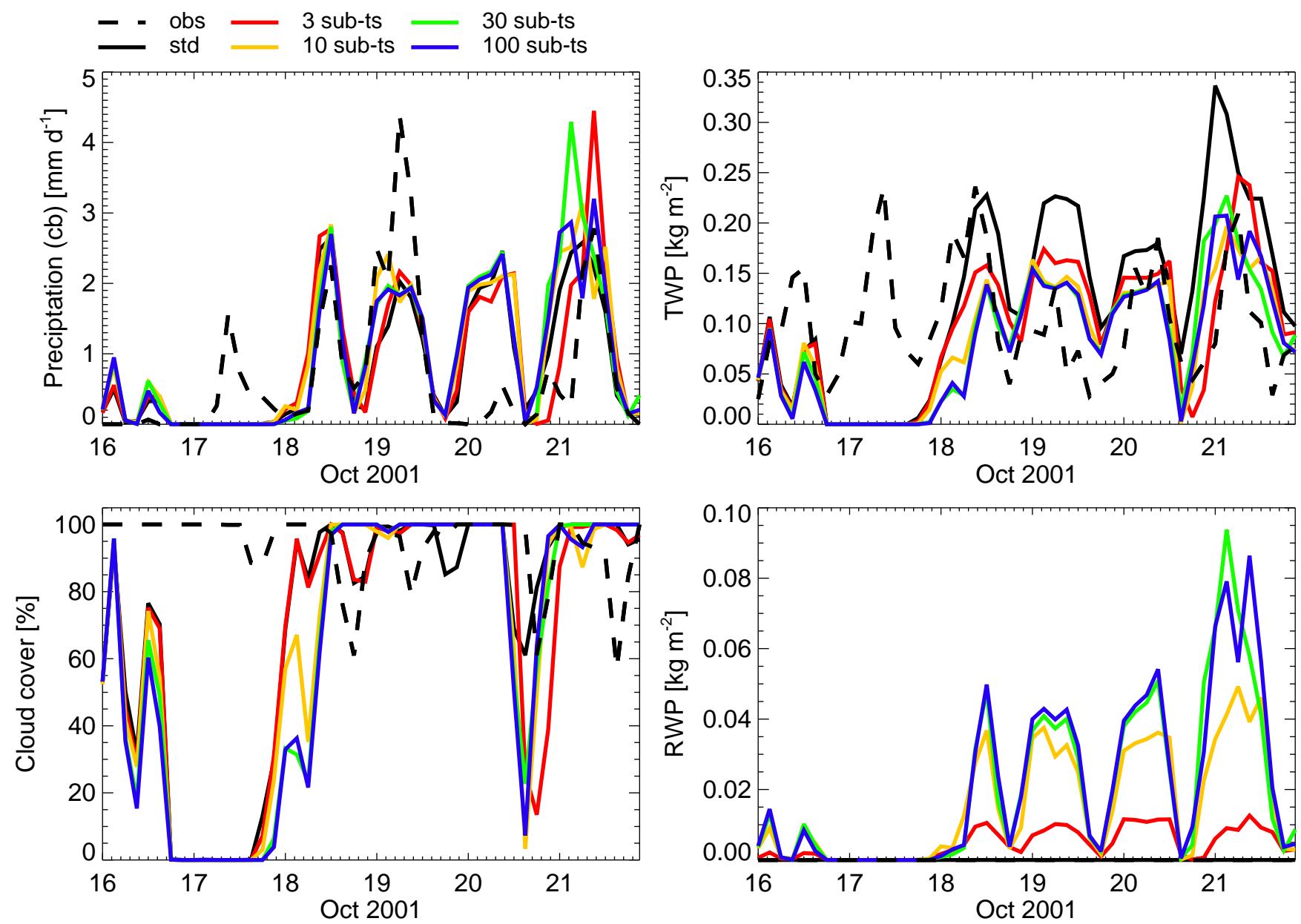

Fig. 3. Precipitation at cloud base (upper left panel), total cloud cover (lower left panel), total liquid water path (upper right panel) and rain water path (lower right panel) from observations during EPIC 2001 (obs) and simulations with ECHAM5-HAM (std) as well as ECHAM5PROG for different sub-time steps $(3,10,30$ and 100)

convection) that result in larger precipitation amounts in the observations. Another factor is the large uncertainty of a factor 2-3 of the radar retrievals (Bretherton et al., 2004). Thus, the difference between observation and simulation could be partly explained by the uncertainties of the measurements.

Similar arguments are valid for the comparison of the total (liquid) water path (TWP) with the observed liquid water in the atmosphere. The observed liquid water path (LWP) was obtained by a microwave radiometer which differentiates between liquid and rain water in another way than ECHAM5 does. Thus, the observed LWP might also include drops which the model assumes to be rain drops. Therefore, the observations are compared with the TWP that is the sum of LWP and RWP (rain water path). The simulations extremely underestimate the TWP at the beginning of the simulation period (see Fig. 3, upper right panel and Table 1). Later on, the agreement between simulations and observations is improved especially for the ECHAM5-PROG simulations which give a lower TWP compared to ECHAM5-DIAG. Al- though the amount is not always simulated correctly the timing of the peaks is captured in most instances. It can be seen that an underestimation of the TWP leads to the missed rain events at the beginning of the considered period. The overestimation of precipitation on October 20th 2001 can not be attributed to the TWP as the TWP for that day is simulated in good agreement with the observations.

The underestimation of the liquid water feeds back on the cloud cover (Fig. 3, lower left panel and Table 1). The model is not able to reproduce the overcast conditions at the beginning of the simulation period. Later on, periods with overcast conditions are reproduced rather well by ECHAM5, whereas in periods with fewer clouds the cloud cover is severely underestimated. However, the overall agreement is quite good.

\subsubsection{Sensitivity to sub-time step number}

For large numbers of sub-time steps the model is converging because the maximum velocity $v_{\max }$ is not reached anymore 
and a shorter time step does not have a large influence on the microphysical parameterizations anymore. Sufficiently large sub-time step numbers would be in the range of 100 and more decreasing the time step length for the rain microphysics to around ten seconds. This is applicable in a SCM without problems but in a GCM high numbers of sub-time steps would drastically increase computational time. Therefore, it is necessary to limit the number of sub-time steps to take the advantage of the prognostic rain but at a reasonable amount of computational cost. Comparing the SCM results for different sub-time steps gives an idea about the optimal number of sub-time steps which then will be used in the GCM simulations.

One criterion to decide on the optimal number of sub-time steps is whether and how often the maximum fall velocity $v_{\max }$ is reached. Fig. 4 shows the relative frequency of the fall velocity $v_{q}$ reaching $v_{\max }$. It can be seen that increasing the number of sub-time steps reduces the occasions when the maximum velocity has to be applied from at most $70 \%$ for the 3 sub-time step simulation to $50 \%$ for the 30 sub-time step simulation. Furthermore, the maximum moves towards the surface, so that at 30 sub-time steps $v_{\max }$ is more or less exclusively reached in the lowest model level. This is caused by decreasing layer heights towards the surface which result in a smaller $v_{\max }$. As expected, a further increase in the number of sub-time steps results in a larger maximum velocity so that the fall velocities are always smaller than $v_{\max }$.

Increasing the number of sub-time steps leads to changes in the autoconversion and accretion rates. More sub-time steps lead to slower sedimentation and thus rain water is kept longer in the atmosphere and is maintained there for the next (model) time step (compared to a diagnostic scheme where all rain water is removed within one time step). Thus, there is generally more rain water in the atmosphere the larger the number of sub-time steps. And more rain water means higher accretion rates. As the accretion process also removes cloud water, less cloud water is available for the autoconversion. Therefore, the autoconversion rates decrease. Thus, the total conversion rate (=autoconversion+accretion rate) increases if the increase in accretion overcompensates the decrease in autoconversion. A decrease of the total conversion rate results if the decrease in autoconversion is larger than the increase in accretion.

Figure 5 shows the vertical profiles of autoconversion, accretion and total conversion rate averaged over the whole simulation period. As expected the autoconversion rate decreases while the accretion increases. The average total conversion rate shows considerable differences only for the 3 sub-time step simulation. The simulation with more subtime steps give quite similar conversion rates. This in turn results in quite similar results for the TWP for 10, 30 and 100 sub-time steps (see Table 1 and Fig. 3). There is no clear dependence of precipitation on the number of sub-time steps. Depending on the precipitation event, a change in the number of sub-time steps can lead to an increase or decrease of

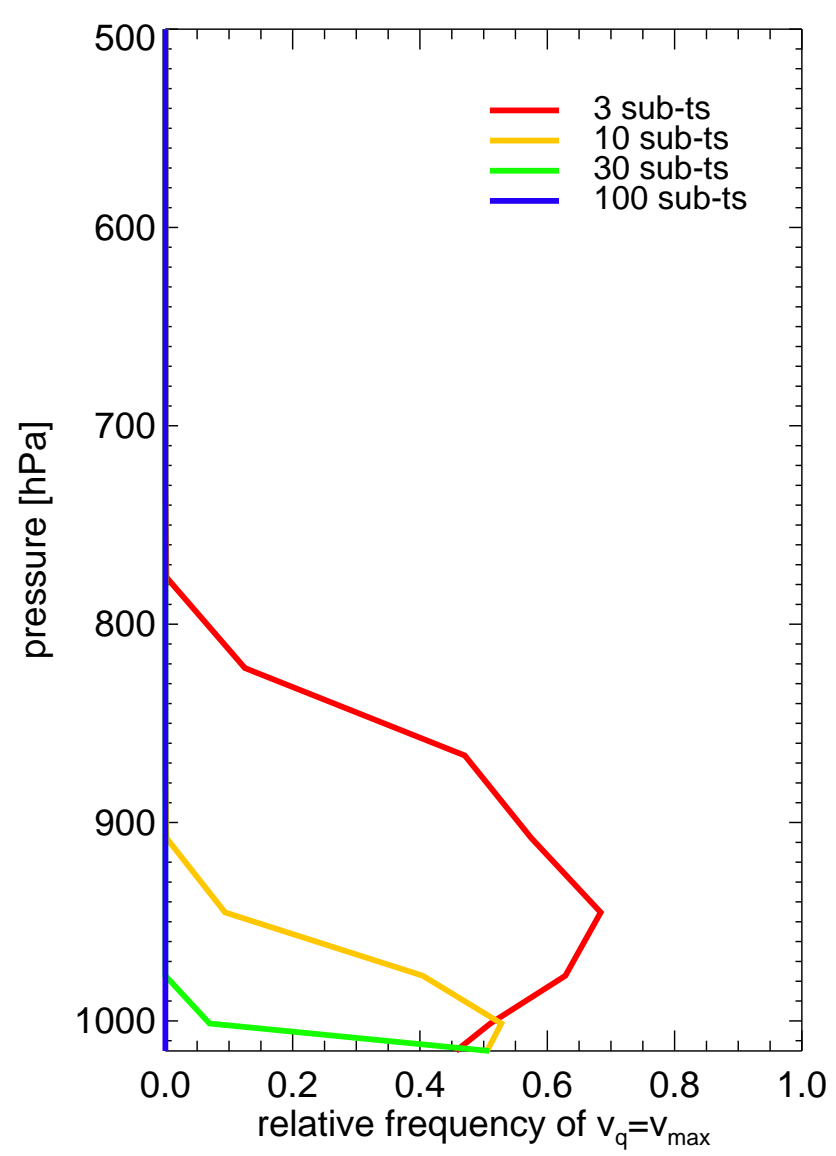

Fig. 4. Relative frequency for $v_{q}=v_{\max }$ for EPIC for different subtime steps $(3,10,30$ and 100)

precipitation and also to slight changes in the timing of the precipitation event. Changes in the cloud cover due to different sub-time steps are small. As they are closely linked to changes in the TWP they do not provide further information.

Moisture budget consideration usually assume that the column integral of the apparent moisture sink (condensation/evaporation) equals the precipitation at the surface plus the evaporation from the surface (surface latent heat flux) (Yanai et al., 1973). Therefore the precipitation is mainly determined by the available moisture. However, in case of diminished or even suppressed autoconversion and accretion due to very low TWP as during EPIC, the precipitation formation depends not only on the available moisture but also on the amount of liquid water in the atmosphere. Liquid water has to accumulate in the atmosphere before the conversion processes can produce precipitation. Therefore, the drizzle case shows some dependence of the precipitation on the number of sub-time steps because the LWP varies with the number of sub-time steps. 

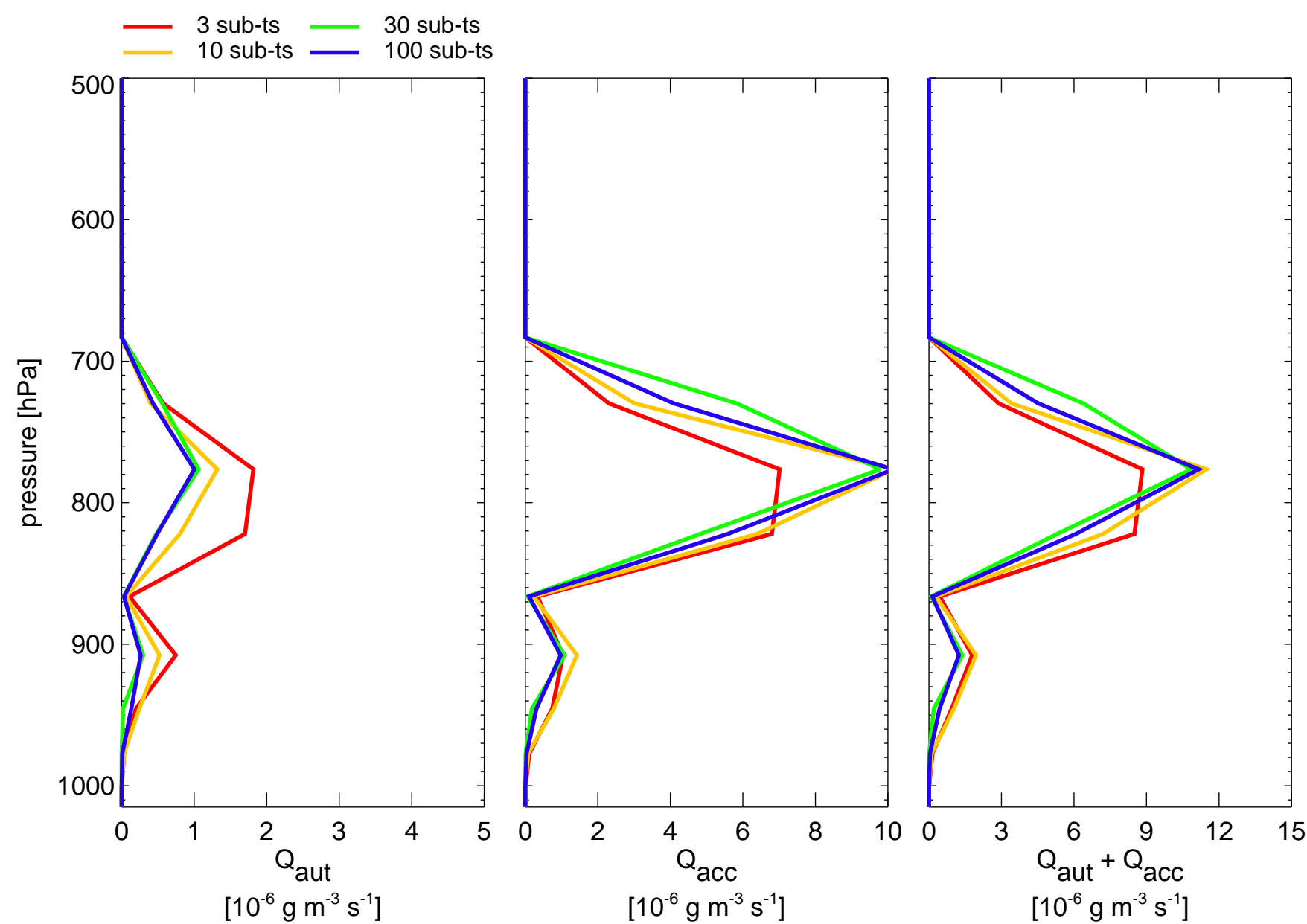

Fig. 5. Vertical profiles of the autoconversion (left panel), accretion (middle panel), and evaporation (right panel) rates from simulations with the ECHAM5-PROG for different sub-time steps (3, 10, 30 and 100) averaged over the whole EPIC 2001 period

Regarding the evolution of TWP and precipitation and the relative frequency of reaching $v_{\max }, 30$ sub-time steps seem to be sufficient to capture the essence of the collisioncoalescence process. The RWP, on the other hand, would need even more sub-time steps before finally converging. However, it seems that it is not important for the surface precipitation how much rain water remains in the atmosphere as long as there is a considerable amount. Therefore, 30 subtime steps seems to be a good compromise.

\subsection{ARM IOP March 2000}

The shallow frontal cloud case of the ARM Cloud IOP in March 2000 described by Xu et al. (2005) was chosen as another case to investigate the changes in the model results between ECHAM5-DIAG and the new version with prognostic equations for rain. At the beginning of the IOP from 1519 March 2000, a cold front moved over the ARM site. Later in this period, a quasi-stationary low pressure system accompanied by frontogenesis characterized the weather con- ditions. Shallow clouds were predominant during the period but occasionally deep clouds also moved over the measurement site. Different to the drizzling EPIC case, the ARM case represents a heavy precipitating case which requires a higher numbers of sub-time steps.

The 5 day SCM simulation is forced with the meteorological conditions and corresponding large-scale horizontal advective tendencies obtained from the ARM Cloud IOP 3-hourly sounding data and surface measurements with additional data from a short-range weather prediction model (RUC-2), the NOAA wind profiler and the NOAA GOES-8 satellite.

\subsubsection{Comparison to observations}

Table 2 gives an overview of the mean variables (precipitation at the surface, total cloud cover, LWP, RWP and TWP) averaged over the whole simulation period for the observations and ECHAM5 simulations. 
Table 2. Same as Table 2 but for the ARM IOP for different sub-time steps (10, 30, 100 and 300)

\begin{tabular}{llccccccc}
\hline & & obs & std & 10 & 30 & 100 & 300 & $10(\mathrm{grad})$ \\
\hline $\begin{array}{l}\text { precipitation } \\
\quad\end{array}$ & & & & & & & \\
surface & {$\left[\mathrm{mm}: d^{-1}\right]$} & 7.29 & 7.52 & 8.08 & 8.10 & 8.10 & 8.11 & 8.11 \\
LWP & {$\left[\mathrm{g}: m^{-2}\right]$} & - & 122.3 & 89.6 & 88.6 & 86.2 & 85.1 & 86.1 \\
RWP & {$\left[\mathrm{g}: m^{-2}\right]$} & - & 0.0 & 23.9 & 46.2 & 63.6 & 69.2 & 24.9 \\
TWP & {$\left[\mathrm{g}: m^{-2}\right]$} & 243.6 & 122.3 & 113.5 & 134.8 & 149.8 & 154.3 & 111.0 \\
Cloud cover & {$[\%]$} & 49.59 & 75.85 & 79.18 & 79.04 & 79.06 & 79.04 & 78.94 \\
\hline
\end{tabular}
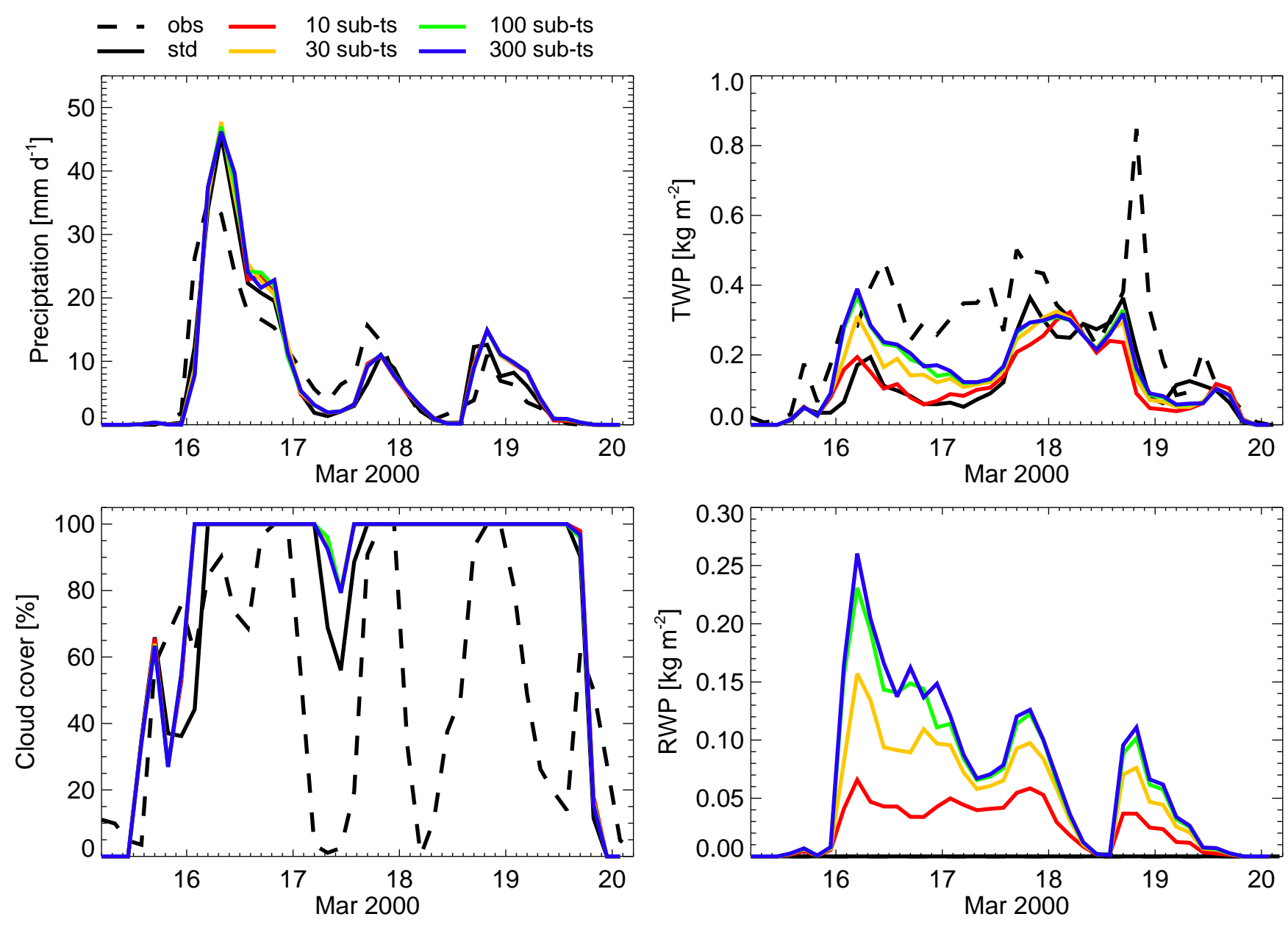

Fig. 6. Precipitation at cloud base (upper left panel), total cloud cover (lower left panel), total liquid water path (upper right panel) and rain water path (lower right panel) from observations during the ARM Cloud IOP (obs) and simulations with ECHAM5-HAM (std) as well as ECHAM5-PROG for different sub-time steps (10, 30, 100 and 300)

The model simulations, regardless of the ECHAM5 version and the number of sub-time steps, are much moister than the observations for the lower troposphere, especially around the cold front passage during the morning of 16 March. This was already shown by Xu et al. (2005) and was explained by a missing advection of hydrometeors out of the model grid box. Thus, the cloud remains in the atmosphere much longer in ECHAM5 as well as in most other SCMs than in reality.
The temporal evolution of the rain rate is shown in Fig. 6 and summarized over the whole simulation period in Table 2. In general, ECHAM5-DIAG and ECHAM5-PROG simulates the precipitation amount equally well although the model simulations overestimate the cold front precipitation at the beginning of the period. This is a direct consequence of the moister environment in the model. 


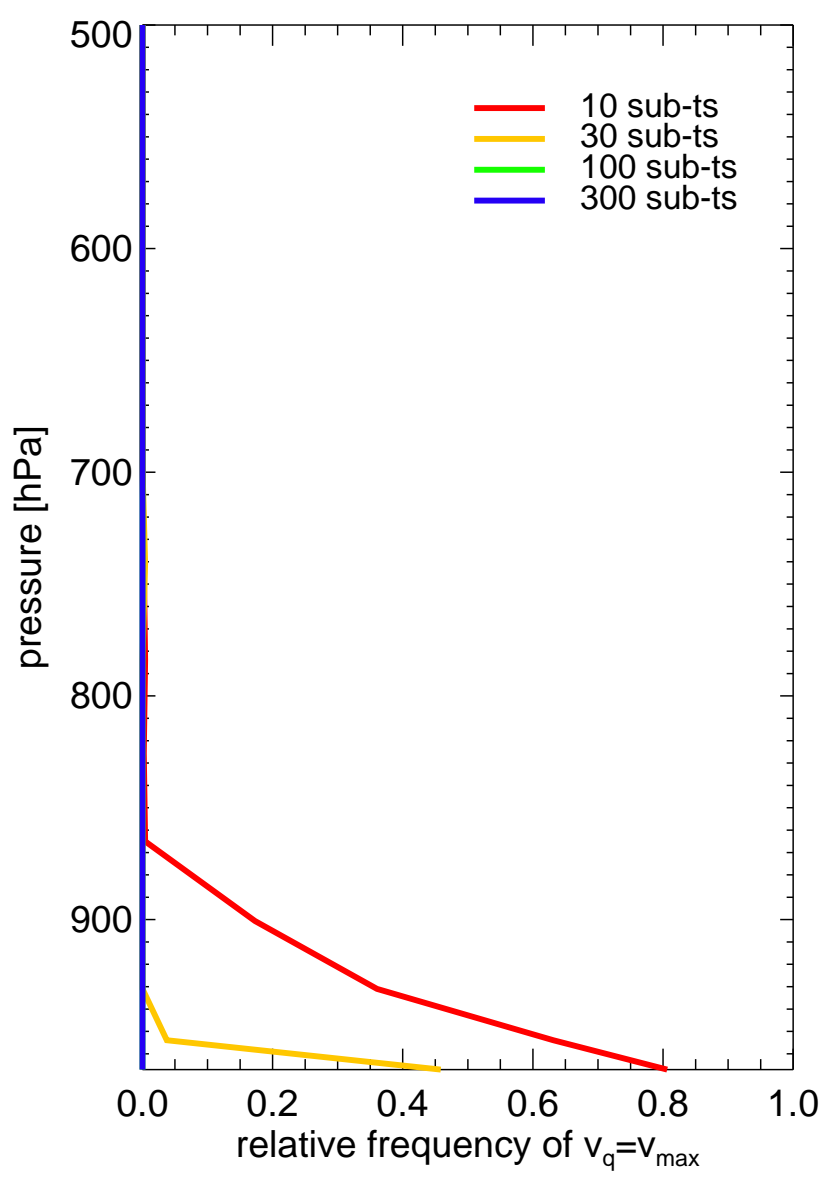

Fig. 7. Relative frequency for $v_{q}=v_{\max }$ for ARM for different subtime steps $(10,30,100$ and 300$)$

The observed LWP was obtained by a millimeter cloud radar (MMCR) (Jensen and Johnson, 2006). The definition of liquid water in this case, which depends on the radar reflectivity, differs from that used in ECHAM5 (and other GCMs) (liquid water=drops with $r<25 \mu \mathrm{m}$ ). Thus, the observed LWP is compared with the TWP of the model. As shown in Fig. 6 and also from Table 2, the model produces a much lower TWP than observed. The observations are characterized by relatively high TWP throughout the whole period. The SCM simulations show a quite low TWP during the cold front passage that is increasing for ECHAM5-PROG with increasing number of sub-time steps due to an accumulation of rain water in the atmosphere (see Fig. 6, upper and lower right panel). For the rest of the period the simulated TWP agrees quite well with the observed TWP but remains on the low side.

The total cloud cover during the IOP is shown in Fig. 6 (lower left panel) and Table 2. The observed total cloud cover is derived from satellite data (GOES satellite) and correlates quite well with the rainy episodes (Fig. 6, upper left panel). The comparison with the TWP shows an inconsistency in the observations such that a non-zero TWP coincides with zero cloud cover. In general, all ECHAM5 simulations reproduce the observed cloud cover quite well. However, the simulated clouds are more persistent and the correlation with precipitation is less pronounced. Thus, the observed average total cloud cover is lower than the simulated total cloud cover (see Table 2).

\subsubsection{Sensitivity to sub-time step number}

Heavy precipitation is usually accompanied by large rain drops with rather high fall velocities. Hence, the treatment of such events in the given prognostic rain scheme requires a rather large number of sub-time steps to reach convergence. However, the precipitation amount itself does not depend on the amount of sub-time steps used. In this case, the amount of precipitation is determined by the large-scale forcing, i.e. by the available moisture, and the evaporation from the surface. Changes in the total water do not affect the precipitation amount but affect the residence time of water in the atmosphere. The increase in total water with a higher number of sub-time steps is mainly determined by the accumulation of rain water in the atmosphere. The cloud water does not depend on the number of sub-time steps nor does the cloud cover (Table 2).

$v_{\max }$ is mainly reached in the lowest model levels as can be seen in Fig. 7. Increasing the sub-time steps decreases the maximum relative frequency from $80 \%$ for 10 sub-time steps to $45 \%$ for 30 sub-time steps. $v_{\max }$ is not reached anymore for 100 or more sub-time steps.

The changes of the microphysical conversion rates are shown in Fig. 8 averaged over the whole IOP. The left panel shows that the autoconversion rate decreases with an increasing number of sub-time steps whereas the accretion rate increases. The total conversion rates show only a very weak dependence on the number of sub-time steps which is reflected in the LWP and the precipitation at the surface.

The rather heavy precipitation during the cold front passage requires even larger numbers of sub-time steps than chosen for this comparison. But the surface precipitation shows no dependence on the number of sub-time steps or even if the diagnostic or prognostic approach is used. Therefore, regarding the precipitation the choice of the sub-time step is irrelevant. That is different for the total water where the largest number of sub-time steps would be the best. But this is not feasible in GCM simulations. Regarding the relative frequency of reaching $v_{\max }, 30$ sub-time steps or more would be most appropriate (similar to EPIC).

\section{Conclusions}

Prognostic equations for the rain mass mixing ratio and rain drop number concentration were introduced into ECHAM5 in order to better represent the accretion process. This requires the introduction of an equation for the fall speed of 

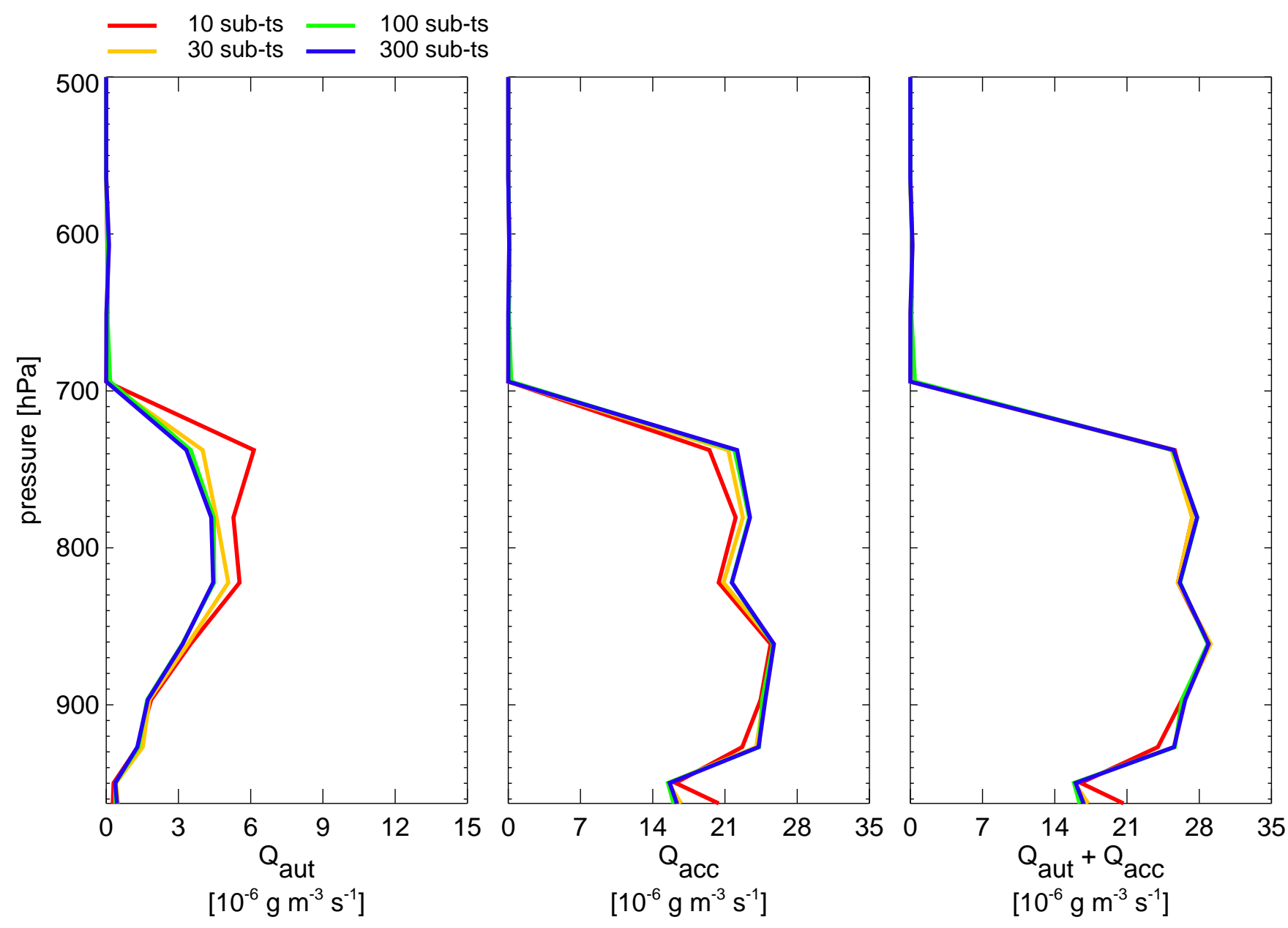

Fig. 8. Vertical profiles of the autoconversion (left panel), accretion (middle panel), and evaporation (right panel) rates from simulations with the ECHAM5-PROG for different sub-time steps (10, 30, 100 and 300) averaged over the whole ARM IOP period

rain drops. To keep the model numerically stable, a maximum vertical velocity, the so-called grid velocity, for each level was defined. With increasing number of time steps, the grid vertical velocity increases. Thus, it is applied less often making the sedimentation process more physical. With the included time-stepping, all microphysical processes associated with rain, e.g. accretion, are better represented.

The marine stratocumulus study of EPIC 2001 and the shallow frontal cloud period during the continental ARM Cloud IOP in March 2000 in Oklahoma were chosen to test the prognostic rain scheme. Five simulations were completed - one with the standard ECHAM5-DIAG and four with the prognostic rain included with a different number of sub-time steps - which were compared with each other and to observations. Generally, ECHAM5-DIAG and ECHAM5-PROG reproduced the observations quite well. A major goal was to find the optimal number of sub-time steps that ensures a good representation of the rain process and that keeps the in- crease in computational cost reasonable. For the drizzle case the number of sub-time steps can be limited to 30 without making large errors in the estimation of the precipitation and the total water amounts. In contrast, precipitation in heavy precipitation events hardly depends on the number of subtime steps or whether a diagnostic or prognostic rain scheme is used. Because a better representation of drizzle was the reason to include a prognostic rain scheme, the future GCM simulations will be carried out with 30 sub-time steps.

Using ECHAM5-PROG does not lead to an overall improvement of the results compared to the diagnostic rain scheme of ECHAM5-DIAG and to the observations. Nevertheless, the more physical description of the precipitation formation process justifies the usage of the new scheme. The presented SCM studies show that the prognostic rain scheme works and yields reasonable results. However, due to the limitations of the SCM approach (e.g., incomplete initial and boundary conditions) final conclusions about the 
improvements with the prognostic rain scheme should be drawn on the basis of global simulations.

The numerical scheme applied for the sedimentation of the rain drops in this study is known to be very simple and has deficiencies regarding numerical diffusion. Thus, future work will also include the implementation of more sophisticated explicit or implicit numerical schemes into ECHAM5PROG. The prognostic treatment of precipitation will be extended to snow as well.

Acknowledgements. The authors thank P. Spichtinger (ETH Zurich) and 2 anonymous reviewers for helpful comments and suggestions and P. Stier (Univ. of Oxford) and S. Ferrachat (ETH Zurich) for their support with the ECHAM5.

Edited by: H. Wernli

\section{References}

Albrecht, B. A.: Aerosols, cloud microphysics, and fractional cloudiness, Science, 245, 1227-1230, 1989.

ARM: ARM Cloud IOP, http://iop.archive.arm.gov/arm-iop/, access: April 2007, 2000.

Beheng, K. D.: A parameterization of warm cloud microphysical conversion processes, Atmos. Res., 33, 193-206, 1994.

Bretherton, C. S., Uttal, T., Fairall, C. W., Yuter, S. E., Weller, R. A., Baumgardner, D., Comstock, K., Wood, R., and Raga, G. B.: The EPIC 2001 stratocumulus study, Bull. Amer. Meteorol. Soc., 85, 967-977, 2004.

Denman, K.L., Brasseur, G., Chidthaisong, A., Ciais, P., Cox, P., Dickinson, R., Hauglustaine, D., Heinze, C., Holland, E., Jacob, D., Lohmann, U., Ramachandran, S., da Silva Dias, P., Wofsy, S., and Zhang, X.: Climate Change 2007: The Physical Science Basis. Contribution of Working Group I to the Fourth Assessment Report of the Intergovernmental Panel on Climate Change, chap. Couplings Between Changes in the Climate System and Biogeochemistry, pp. 499-588, Cambridge University Press, Cambridge, United Kingdom and New York, NY, USA, 2007.

EPIC: EPIC Integrated Dataset, http://www.atmos.washington.edu/ $\sim$ caldwep/research/ScDataset/sc_integ_data_fr.htm, last access: April 2007, 2005.

Feingold, G., Cotton, W. R., Kreidenweis, S. M., and Davis, J. T.: The impact of giant cloud condensation nuclei on drizzle formation in stratocumulus: Implications for cloud radiative properties, J. Atmos. Sci., 56, 4100-4117, 1999.

Fowler, L. D., Randall, D. A., and Rutledge, S. A.: Liquid and ice cloud microphysics in the CSU general circulation model. Part I: Model description and simulated microphysical processes, J. Clim., 9, 489-529, 1996.

Ghan, S. J. and Easter, R. C.: Computationally efficient approximations to stratiform cloud microphysics parameterization, Mon. Weather Rev., 120, 1572-1582, 1992.

Grabowski, W. W.: Toward cloud resolving modeling of large-scale tropical circulations: A simple cloud microphysics parameterization, J. Atmos. Sci., 55, 3283-3298, 1998.
Grabowski, W. W.: A parameterization of cloud microphysics for long-term cloud-resolving modeling of tropical convection, Atmos. Res., 52, 17-41, 1999.

Grabowski, W. W. and Smolarkiewicz, P. K.: A multiscale anelastic model for meteorological research, Mon. Weather Rev., 130, 939-956, 2002.

Hatfield, J. L. and Prueger, J. H.: Impacts of changing precipitation patterns on water quality, J. Soil Water Conserv., 59, 51-58, 2004.

Jensen, M. and Johnson, K.: 3rd ARM Quaterly Report: Continuous Profiles of Cloud Microphysical Properties for the Fixed Atmospheric Radiation Measurement Sites (DOE/SC-ARM/P0609), Tech. rep., Atmospheric Radiation Measurement (ARM) Program, 2006.

Johnson, D. B.: The Role of Giant and Ultragiant Aerosol Particles in Warm Rain Initiation, J. Atmos. Sci., 39, 448-460, 1982.

Khairoutdinov, M. and Kogan, Y.: A New Cloud Physics Parameterization in a Large-Eddy Simulation Model of Marine Stratocumulus , Mon. Weather Rev., 128, 229-243, 2000.

Lohmann, U. and Feichter, J.: Global indirect aerosol effects: a review, Atmos. Chem. Phys., 5, 715-737, 2005, http://www.atmos-chem-phys.net/5/715/2005/.

Lohmann, U. and Roeckner, E.: Design and performance of a new cloud microphysics scheme developed for the ECHAM general circulation model, Clim. Dyn., 12, 557-572, 1996.

Lohmann, U., Feichter, J., Chuang, C. C., and Penner, J. E.: Prediction of the number of cloud droplets in the ECHAM GCM, J. Geophys. Res.-Atmos., 104, 9169-9198, 1999.

Lohmann, U., Stier, P., Hoose, C., Ferrachat, S., Kloster, S., Roeckner, E., and Zhang, J.: Cloud microphysics and aerosol indirect effects in the global climate model ECHAM5-HAM, Atmos. Chem. Phys., 7, 3425-3446, 2007, http://www.atmos-chem-phys.net/7/3425/2007/.

Lopez, P.: Implementation and validation of a new prognostic large-scale cloud and precipitation scheme for climate and dataassimilation purposes, Q. J. R. Meteor. Soc., 128, 229-257, 2002.

Marshall, J. S. and Palmer, W. M.: The distribution of raindrops with size, J. Meteorol., 5, 165-166, 1948.

Müller, M.: Sedimentation of hydrometeors in ECHAM, Master's thesis, ETH Zurich, 2007.

Penner, J. E., Quaas, J., Storelvmo, T., Takemura, T., Boucher, O., Guo, H., Kirkevag, A., Kristjansson, J. E., and Seland, O.: Model intercomparison of indirect aerosol effects, Atmos. Chem. Phys., 6, 3391-3405, 2006,

http://www.atmos-chem-phys.net/6/3391/2006/.

Posselt, R. and Lohmann, U.: Influence of Giant CCN on warm rain processes in the ECHAM5 GCM, Atmos. Chem. Phys. Discuss., 7, 14 767-14 811, 2007.

Pruppacher, H. R. and Klett, J. D.: Microphysics of Clouds and Precipitation, Kluwer Academic Publishers, 1997.

Roeckner, E., Bäuml, G., Bonaventura, L., Brokopf, R., Esch, M., Giorgetta, M., Hagemann, S., Kirchner, I., Kornblueh, L., Manzini, E., Rhodin, A., Schlese, U., Schulzweida, U., and Tompkins: The atmospheric general circulation modell ECHAM5, Part I: Model description, Tech. Rep. 349, MaxPlanck-Institute for Meteorology, Hamburg, Germany, 2003.

Rogers, R. R. and Yau, M. K.: A short course in cloud physics, Butterworth-Heinemann (Elsevier Science), 3 edn., 1989.

Rogers, R. R., Baumgardner, D., Ethier, S. A., Carter, D. A., and 
Ecklund, W. L.: Comparison of raindrop size distributions measured by radar wind profiler and by airplane, J. Appl. Meteorol., 32, 694-699, 1993.

Rosenfeld, D.: Suppression of rain and snow by urban and industrial air pollution, Science, 287, 17931796, http://links.isiglobalnet2.com/gateway/Gateway.cgi? GWVersion $=1 \&$ SrcAuth $=$ KBib $\&$ SrcApp $=$ KBib $\&$ KeyUT $=$ $000085775300034,2000$.

Rosenfeld, D., Lahav, R., Khain, A., and Pinsky, M.: The role of sea spray in cleansing air pollution over ocean via cloud processes, Science, 297, 1667-1670, 2002.

Rotstayn, L. D.: A physically based scheme for the treatment of stratiform clouds and precipitation in large-scale models (1): Description and evaluation of the microphysical processes, Q. J. R. Meteor. Soc., 123, 1227-1282, 1997.

Smolarkiewicz, P. K. and Margolin, L. G.: On forward-in-time differencing for fluids: An Eulerian/semi-Lagrangian nonhydrostatic model for stratified flows, Atmos-Ocean Special, 35, 127157, 1997.

Smolarkiewicz, P. K. and Margolin, L. G.: MPDATA: A finitedifference solver for geophysical flows, J. Comput. Phys., 140, 459-480, 1998.

Srivastava, R. C.: Parameterization of raindrop size distributions, J. Atmos. Sci., 35, 108-117, 1978.

Stier, P., Feichter, J., Kinne, S., Kloster, S., Vignati, E., Wilson, J., Ganzeveld, L., Tegen, I., Werner, M., Balkanski, Y., Schulz, M., and Boucher, O.: The aerosol-climate model ECHAM5-HAM, Atmos. Chem. Phys., 5, 1125-1156, 2005, http://www.atmos-chem-phys.net/5/1125/2005/.
Storelvmo, T., Kristjansson, J. E., Myhre, G., Johnsrud, M., and Stordal, F.: Combined observational and modeling based study of the aerosol indirect effect, Atmos. Chem. Phys., 6, 3583-3601, 2006, http://www.atmos-chem-phys.net/6/3583/2006/.

Tompkins, A. M.: A prognostic parameterization for the subgridscale variability of water vapor and clouds in large-scale models and its use to diagnose cloud cover, J. Atmos. Sci., 59, 19171942, 2002.

Twomey, S.: Pollution and planetary albedo, Atmos. Environ., 8, 1251-1256, 1974

Wood, R.: Drizzle in stratiform boundary layer clouds. Part II: Microphysical aspects, J. Atmos. Sci., 62, 3034-3050, 2005.

Xu, K. M., Zhang, M. H., Eitzen, M. A., Ghan, S. J., Klein, S. A., Wu, X. Q., Xie, S. C., Branson, M., Genio, A. D. D., Iacobellis, S. F., Khairoutdinov, M., Lin, W. Y., Lohmann, U., Randall, D. A., Somerville, R. C. J., Sud, Y. C., Walker, G. K., Wolf, A., Yio, J. J., and Zhang, J. H.: Modeling springtime shallow frontal clouds with cloud-resolving and single-column models, J. Geophys. Res.-Atmos., 110, D15S04, doi:doi:10.1029/2004JD005153, 2005.

Yanai, M., Esbensen, S., and Chu, J. H.: Determination of bulk properties of tropical cloud clusters from large-scale heat and moisture budgets, J. Atmos. Sci., 30, 611-627, 1973. 